\title{
Image-Based Multi-Scale Simulation and Experimental Validation of Thermal Conductivity of Lanthanum Zirconate
}

Xingye Guo ${ }^{\mathrm{a}}$, Bin $\mathrm{Hu}^{\mathrm{b}}$, Changdong Wei ${ }^{\mathrm{c}}$, Jiangang Sun ${ }^{\mathrm{d}}$, Yeon-Gil Jung ${ }^{\mathrm{e}}, \mathrm{Li} \mathrm{Li}^{\mathrm{f}}, \mathrm{James}$ Knapp $^{\text {f }}$, Jing Zhang ${ }^{\mathrm{a} *}$

a Department of Mechanical Engineering, Indiana University-Purdue University Indianapolis, IN 46202, USA

b Thayer School of Engineering, Dartmouth College, Hanover, NH 03755, USA

c Department of Material Science and Engineering, Ohio State University, Columbus, OH 43210, USA

d Nuclear Engineering Division, Argonne National Laboratory, Argonne, IL 60439, USA

e School of Nano and Advanced Materials Engineering, Changwon National University, Changwon, Gyeongnam 641-773, Republic of Korea

f Praxair Surface Technologies, Indianapolis, IN 46222, USA

*Corresponding author: jz29@iupui.edu

\begin{abstract}
Lanthanum zirconate $\left(\mathrm{La}_{2} \mathrm{Zr}_{2} \mathrm{O}_{7}\right)$ is a promising candidate material for thermal barrier coating (TBC) applications due to its low thermal conductivity and high-temperature phase stability. In this work, a novel image-based multi-scale simulation framework combining molecular dynamics (MD) and finite element (FE) calculations is proposed to study the thermal conductivity of $\mathrm{La}_{2} \mathrm{Zr}_{2} \mathrm{O}_{7}$ coatings. Since there is no experimental data of single crystal $\mathrm{La}_{2} \mathrm{Zr}_{2} \mathrm{O}_{7}$ thermal conductivity, a reverse non-equilibrium molecular dynamics (reverse NEMD) approach is first employed to compute the temperature-
\end{abstract}


dependent thermal conductivity of single crystal $\mathrm{La}_{2} \mathrm{Zr}_{2} \mathrm{O}_{7}$. The single crystal data is then passed to a FE model which takes into account of realistic thermal barrier coating microstructures. The predicted thermal conductivities from the FE model are in good agreement with experimental validations using both flash laser technique and pulsed thermal imaging-multilayer analysis. The framework proposed in this work provides a powerful tool for future design of advanced coating systems.

Keywords: Lanthanum zirconate; thermal conductivity; molecular dynamics; finite element; microstructure; imaging; flash laser technique; pulsed thermal imagingmultilayer analysis 


\section{Introduction}

Thermal barrier coatings (TBCs) are multi-layered ceramic coating systems deposited on turbine and combustor parts, which provide thermal insulation to the metallic substrate and improve the durability and energy efficiency of gas turbines [1,2]. Typically, TBCs are deposited by using air plasma spray (APS) or by electron beam physical vapor deposition (EB-PVD) process. The primary requirements of TBCs for the turbine designer are low thermal conductivity and low density to minimize centrifugal loads [3, 4]. Other basic requirements include high-temperature phase stability, high thermal expansion coefficient, and low sintering activity [5, 6]. Recently, lanthanum zirconate has become a very promising candidate for thermal barrier coating applications, because it has low thermal conductivity and high-temperature phase stability. A transmission electron microscopy (TEM) image of $\mathrm{La}_{2} \mathrm{Zr}_{2} \mathrm{O}_{7}$ coating powder is shown in Fig. 1 .

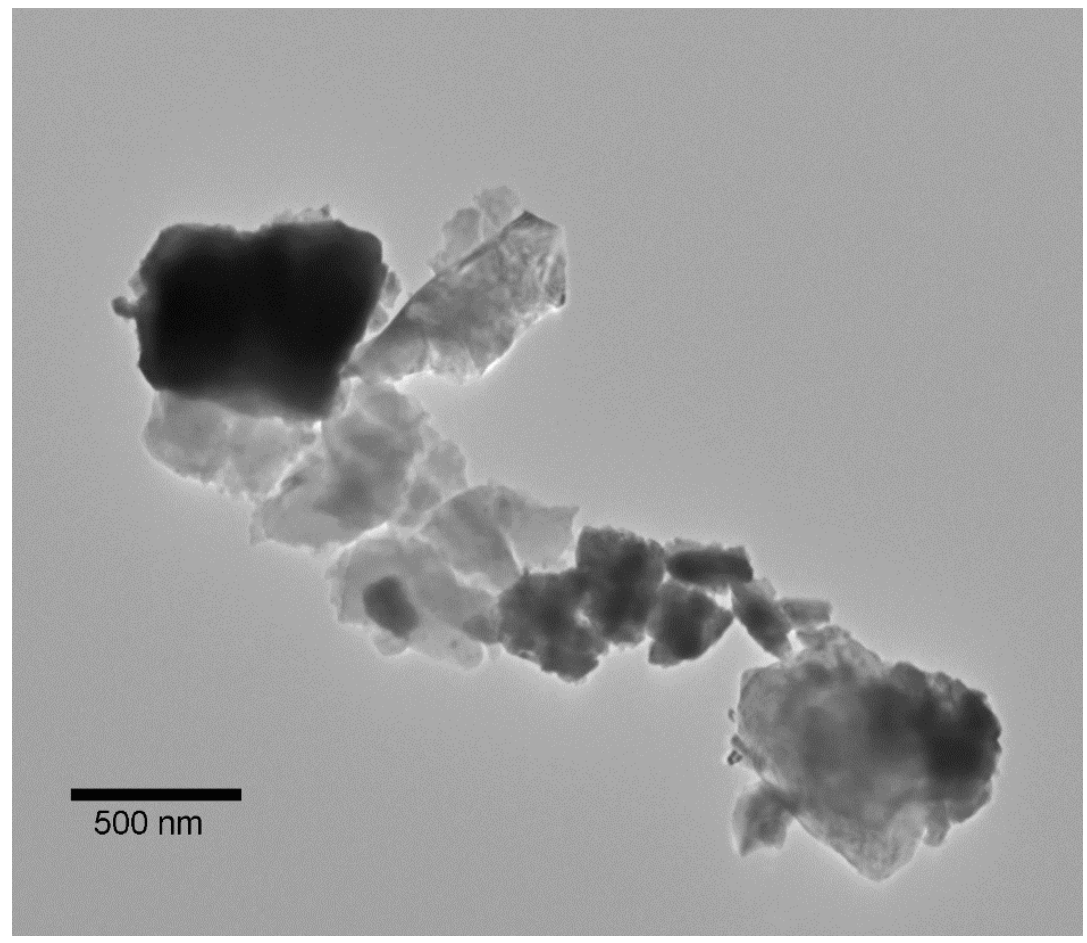

Figure 1: TEM image of $\mathrm{La}_{2} \mathrm{Zr}_{2} \mathrm{O}_{7}$ coating powder

For thermal barrier coating materials, one of the most important material properties is thermal conductivity. There are several experimental methods to measure thermal conductivity. The most common one is flash method, which was first proposed by Parker 
et al. [7]. Three thermal properties - thermal diffusivity, specific heat capacity and thermal conductivity - can be deduced simultaneously using one sample [7]. The flash method is designated as the standard thermal diffusivity method specified in ASTM E1461-11. The measurement error of the standard flash method is less than $5 \%$ [8]. Using flash method, Vassen et al. measured the thermal conductivity of hot pressed fully dense $\mathrm{La}_{2} \mathrm{Zr}_{2} \mathrm{O}_{7}$ disk samples to be $1.5 \sim 2.0 \mathrm{~W} / \mathrm{m} / \mathrm{K}$ in a temperature range of 200 1500 ${ }^{\circ} \mathrm{C}$ [5]. Zhu et al. did similar studies for hot pressed disk samples using $\mathrm{La}_{2} \mathrm{Zr}_{2} \mathrm{O}_{7}$ spraydried $\mathrm{La}_{2} \mathrm{Zr}_{2} \mathrm{O}_{7}$ powders $[9,10]$. The measured thermal conductivities were 1.9 3.0 $\mathrm{W} / \mathrm{m} / \mathrm{K}$ in a temperature range of $200 \sim 1600{ }^{\circ} \mathrm{C}$. We measured thermal conductivities for porous $8 \mathrm{wt} \%$ yttria stabilized zirconia ( $8 \mathrm{YSZ}$ ) coating and porous $\mathrm{La}_{2} \mathrm{Zr}_{2} \mathrm{O}_{7}$ coating using flash method in our previous work [11]. The measured average thermal conductivity of $\mathrm{La}_{2} \mathrm{Zr}_{2} \mathrm{O}_{7}$ (porosity 11.54\%) was about $0.59 \sim 0.68 \mathrm{~W} / \mathrm{m} / \mathrm{K}$ at the temperature range of 297 to $1172 \mathrm{~K}\left(24 \sim 899{ }^{\circ} \mathrm{C}\right)$, which was about $25 \%$ lower than that of porous $8 \mathrm{YSZ}$ at the same temperature range.

In parallel to experimental technique, molecular dynamics (MD) method can also be used to investigate the thermal conductivity. For single crystals, there are two common molecular dynamics methods for thermal conductivity calculations, i.e., direct method $[12,13]$ and Green-Kubo method $[14,15]$. The direct method is a non-equilibrium molecular dynamics (NEMD) method, which imposes a temperature gradient to the system. The Green-Kubo method is an equilibrium MD (EMD) method, which uses the current fluctuation to calculate the thermal conductivity according to the fluctuationdissipation theorem [16]. Schelling et al. predicted the thermal conductivities of several dozens of single crystal pyrochlores with composition of $\mathrm{A}_{2} \mathrm{~B}_{2} \mathrm{O}_{7}$ ( $\mathrm{A}$ is a rare element, and $\mathrm{B}=\mathrm{Ti}$, Mo, $\mathrm{Sn}, \mathrm{Zr}$ or $\mathrm{Pb}$ ) using the NEMD methods with Buckingham potentials [12]. The calculated thermal conductivity of single crystal $\mathrm{La}_{2} \mathrm{Zr}_{2} \mathrm{O}_{7}$ was $1.98 \mathrm{~W} / \mathrm{m} / \mathrm{K}$ at 1200 ${ }^{\circ} \mathrm{C}$ [12]. A more reliable method to compute thermal conductivity is the reverse NEMD (RNEMD) method [17]. In RNEMD method, the Muller-Plathe algorithm [18] is used to exchange kinetic energy between two atoms in different regions of the simulation box every finite steps to induce a temperature gradient in the system. It works by exchanging velocities between two atoms in different parts of the simulation cell. At set intervals, the velocity of the fastest atom in one region is replaced by the velocity of the slowest atom 
in another region, and vice versa. Consequently, the first region become colder, whereas the second region increases in temperature. The system will react by flowing energy from the hot to the cold region. Eventually a steady state sets in when the energy exchanged offsets the energy flowing back with a temperature gradient over the space between the two regions. This enables the thermal conductivity of a material to be calculated. The usual NEMD approach is to impose a temperature gradient on the system and measure the response as the resulting heat flux. In RNEMD using the Muller-Plathe algorithm, the heat flux is imposed, and the temperature gradient is the system's response. The advantage of NEMD over traditional NEMD is that there are no artificial "temperature walls" in the simulated system, since these cause a fluid structure different from the bulk. Additionally, energy and momentum are conserved, and there are no thermostat issues [17]. We have calculated thermal properties of $\mathrm{La}_{2} \mathrm{Zr}_{2} \mathrm{O}_{7}$ such as specific heat and coefficient of thermal expansion (CTE) in our previous work [19, 20]. In this work, we will compute temperature-dependent thermal conductivity of $\mathrm{La}_{2} \mathrm{Zr}_{2} \mathrm{O}_{7}$ single crystal using RNEMD method to provide data in later finite element model in order to compare against experimental data. As shown in the TEM image in Fig. 1, there are very few defects in the crystal, therefore $\mathrm{La}_{2} \mathrm{Zr}_{2} \mathrm{O}_{7}$ single crystal can be described by using molecular dynamics model.

Finite element (FE) method can be used to simulate the heat conduction process of coating structures with cracks and pores [21]. In addition, quantitative imaging analysis method has been used to investigate the non-uniformity properties of the porous coating with polycrystalline microstructure [22, 23]. Pore and crack morphology of thermal barrier coating are important parameters affecting the mechanical and thermal properties $[24,25]$. The thermal properties of non-uniform porous polycrystalline coatings can be calculated using image based FE method. Image based FE method uses scanning electron microscope (SEM) images to generate microstructures and import into a FE model [26]. Arai et al. studied the thermal conductivities of TBCs with different porosities using SEM image based FE modeling [25]. They found that the presence of the pores disturbed heat flow in materials. In addition, the thermal conductivity of plasma sprayed porous yttria-stabilized zirconia (YSZ) was investigated by several researchers using FE method 
$[27,28]$. The calculated effective thermal conductivities were in good agreement with experimental results.

In this paper, we propose a novel image-based multi-scale simulation framework combining molecular dynamics and finite element calculations to study the thermal conductivity of $\mathrm{La}_{2} \mathrm{Zr}_{2} \mathrm{O}_{7}$ thermal barrier coating. Since there is no experimental thermal conductivity data of $\mathrm{La}_{2} \mathrm{Zr}_{2} \mathrm{O}_{7}$ single crystal, a reverse non-equilibrium molecular dynamics approach is first used to compute the temperature-dependent thermal conductivity of $\mathrm{La}_{2} \mathrm{Zr}_{2} \mathrm{O}_{7}$ single crystal. The single crystal data is then passed to a FE model with realistic thermal barrier coating microstructures generated using SEM images. The predicted thermal conductivities from the FE model are compared against experimentally measured thermal conductivity using both flash laser technique and pulsed thermal imaging-multilayer analysis.

\section{Method}

\subsection{Multi-scale simulation of thermal conductivity}

For $\mathrm{La}_{2} \mathrm{Zr}_{2} \mathrm{O}_{7}$ single crystal, the RNEMD method is used to predict temperaturedependent thermal conductivity. The $\mathrm{La}_{2} \mathrm{Zr}_{2} \mathrm{O}_{7}$ unit cell is a face-centered cubic pyrochlore structure with a lattice parameter of $10.8 \AA$ [19]. $\mathrm{A} \mathrm{La}_{2} \mathrm{Zr}_{2} \mathrm{O}_{7}$ supercell model with the dimension of $324 \times 21.6 \times 21.6 \AA^{3}$ has total 10560 atoms, including $6720 \mathrm{O}$ atoms, $1920 \mathrm{La}$ atoms and $1920 \mathrm{Zr}$ atoms. The supercell model is sliced into 30 layers with equal thickness. A temperature decay constant $0.1 \mathrm{ps}$ is imposed in each layer. The thermal conductivity follows as the energy flux divided by the temperature gradient [17]:

$$
k=\frac{\dot{q}}{d T / d x}
$$

where $k$ is thermal conductivity, $\dot{q}$ is heat flux defined by the amount of heat (Q) transferred per unit time per unit area in heat transfer direction; $\partial \mathrm{T} / \partial \mathrm{z}$ is temperature gradient in the heat transfer direction. 
For the image-based FE models, representative SEM images of cross-sectional view of the porous $\mathrm{La}_{2} \mathrm{Zr}_{2} \mathrm{O}_{7}$ thermal barrier coating are converted into binary images using ImageJ software package [29]. In the binary images, white color regions represent solid $\mathrm{La}_{2} \mathrm{Zr}_{2} \mathrm{O}_{7}$ coating phase, and black color regions are pores and cracks. The binary images then are passed into to a FE software package, COMSOL Multiphysics [30], to automatically generate FE meshes. In the FE models, a constant temperature difference boundary condition is applied at the top $\left(\mathrm{T}_{\text {top }}\right)$ and bottom $\left(\mathrm{T}_{\text {bot }}\right)$ surface of the system, with the average temperature $\left(\mathrm{T}_{\text {top }} / 2+\mathrm{T}_{\text {bot }} / 2\right)$ as the target temperatures, $473 \sim 1273 \mathrm{~K}$. The pores and cracks are filled with non-flowing air. Zero thermal conductivity is assumed for the pores and cracks, because the thermal conductivity of non-flowing air is much smaller than that of the coating $[27,31]$. For $\mathrm{La}_{2} \mathrm{Zr}_{2} \mathrm{O}_{7}$ coating solid phase, the calculated temperature-dependent thermal conductivities of $\mathrm{La}_{2} \mathrm{Zr}_{2} \mathrm{O}_{7}$ single crystal from RNEMD are used.

\subsection{Experimental measurements of thermal conductivity}

In the flash method, a high-intensity short-duration laser pulse is lighted on the front surface of the sample, and the temperature in the rear surface is measured by an infrared detector. The thermal conductivity is determined from the relationship [7, 32]:

$$
k=D_{t h}(t) \cdot C_{p}(t) \cdot \rho(t)
$$

where $D_{t h}(t)$ is thermal diffusivity as a function of time $t, C_{p}(t)$ is specific heat at constant pressure, and $\rho(t)$ is density. The density $\rho(t)$ is measured following ASTM standard B328-94. The measurement includes an analytical balance (Mettler AE240, Switzerland) and a density determination kit (Denver Instrument, Arvada, Colorado). Both thermal diffusivity and specific heat capacity are measured by flash diffusivity systems DLF 1200 (TA Instrument, Delaware). In this work, all porous $\mathrm{La}_{2} \mathrm{Zr}_{2} \mathrm{O}_{7}$ thermal barrier coating samples were produced by using air plasma spray technique. The thickness of the porous $\mathrm{La}_{2} \mathrm{Zr}_{2} \mathrm{O}_{7}$ top coat varies from 450 to $550 \mu \mathrm{m}$. The density of sprayed $\mathrm{La}_{2} \mathrm{Zr}_{2} \mathrm{O}_{7}$ coating ranges from 5.18 to $5.26 \mathrm{~g} / \mathrm{cm}^{3}$, with the corresponding porosity ranges from $12.33 \%$ to 
$13.61 \%$. The porosity is essential for reducing thermal conductivity while maintaining resisting fracture, erosion and foreign object damage [3].

Pulsed thermal imaging-multilayer analysis (PTI-MLA) method is recently developed as a new method to measure the thermal conductivity [33], to overcome a few limitations in the flash method. For example, the flash method requires two sides accessible for the specimens. The sample surface is destructed by the laser flash. In addition, the flash method obtains a single averaged thermal conductivity of the sample, and it does not provide spatial distribution of the thermal conductivity [33]. In comparison, the PTIMLA technique is a one-sided experimental system, which consists a photographic flash lamp (Source 6400; BALCAR, France), an infrared filter and a mid-wavelength $(3 \sim 5 \mu \mathrm{m})$ infrared camera (Phoenix, FLIR). PTI-MLA method is based on monitoring the surface temperature decay, after it is applied with a pulsed thermal energy that is transferred inside the sample gradually [33].

\section{Results and discussion}

\section{1 $\mathrm{La}_{2} \mathrm{Zr}_{2} \mathrm{O}_{7}$ single crystal RNEMD thermal conductivity calculation}

The optimized $\mathrm{La}_{2} \mathrm{Zr}_{2} \mathrm{O}_{7}$ single crystal unit cell has a lattice parameter of $10.8 \AA$ which is used to in construction of a supercell in the RNEMD thermal conductivity calculations. The calculated temperature distribution in the supercell is shown in Fig. 2. There are two high temperature hot zones at the ends, and a low temperature cold zone in the middle for generating a temperature gradient. The target temperature in Fig. 2 is $1273 \mathrm{~K}$ which is the average temperature in the supercell.

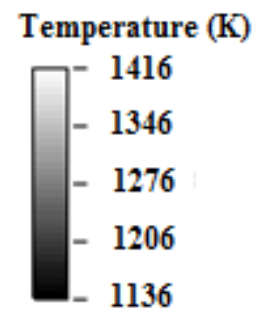

Figure 2: Temperature distribution in $\mathrm{La}_{2} \mathrm{Zr}_{2} \mathrm{O}_{7}$ single crystal supercell at $1273 \mathrm{~K}$ 
The temperature gradient along the heat flux direction in the supercell is plotted in Fig. 3. Two linear temperature gradients are identified and can be used to calculate the thermal conductivity using Eq. 1.

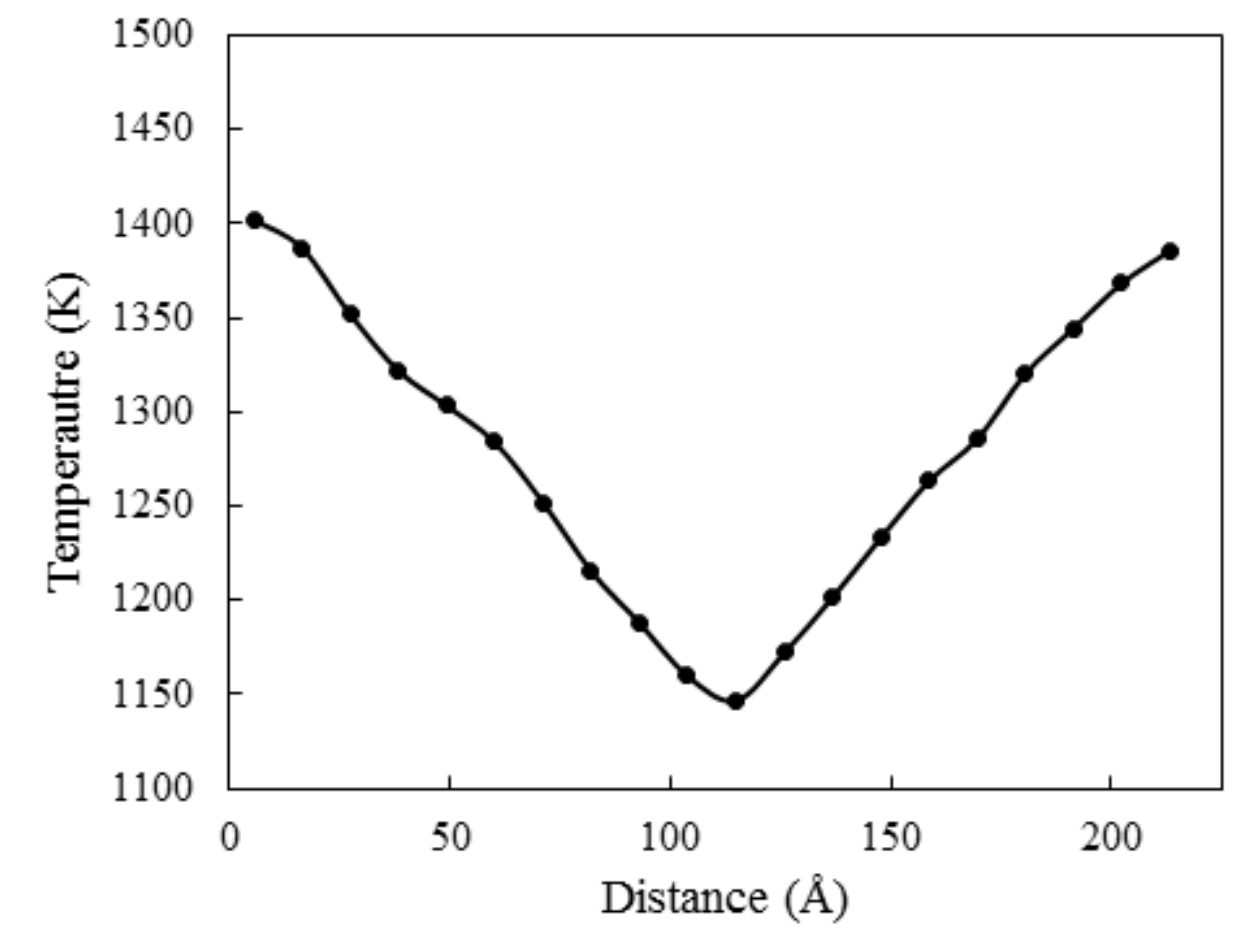

Figure 3: Temperature distribution along the heat flux direction in $\mathrm{La}_{2} \mathrm{Zr}_{2} \mathrm{O}_{7}$ single crystal supercell.

The calculated temperature-dependent thermal conductivity of $\mathrm{La}_{2} \mathrm{Zr}_{2} \mathrm{O}_{7}$ single crystal is shown in Fig. 4. The thermal conductivity values range from 1.25 to $1.39 \mathrm{~W} / \mathrm{m} / \mathrm{K}$ in the temperature range of $473 \sim 1273 \mathrm{~K}$. It is noted that thermal radiation effect at high temperatures is not considered in this RNEMD model. Our predicted $\mathrm{La}_{2} \mathrm{Zr}_{2} \mathrm{O}_{7}$ single crystal thermal conductivity is lower than Schelling's NEMD result $(1.98 \mathrm{~W} / \mathrm{m} / \mathrm{K}$ at 1200 $\left.{ }^{\circ} \mathrm{C}[12]\right)$, probably due to two factors. One is the method, Schelling used NEMD and we use RNEMD. The second is the different force fields used in the model. Schelling used Buckingham potentials and we use universal force field. Schelling's single crystal result compared reasonably well with fully dense polycrystalline experimental data. However, the influence of microstructure in the polycrystalline was not considered. In our model, 
we also calculate temperature-dependent thermal conductivity of polycrystalline $\mathrm{La}_{2} \mathrm{Zr}_{2} \mathrm{O}_{7}$ using the FE model as discussed below.

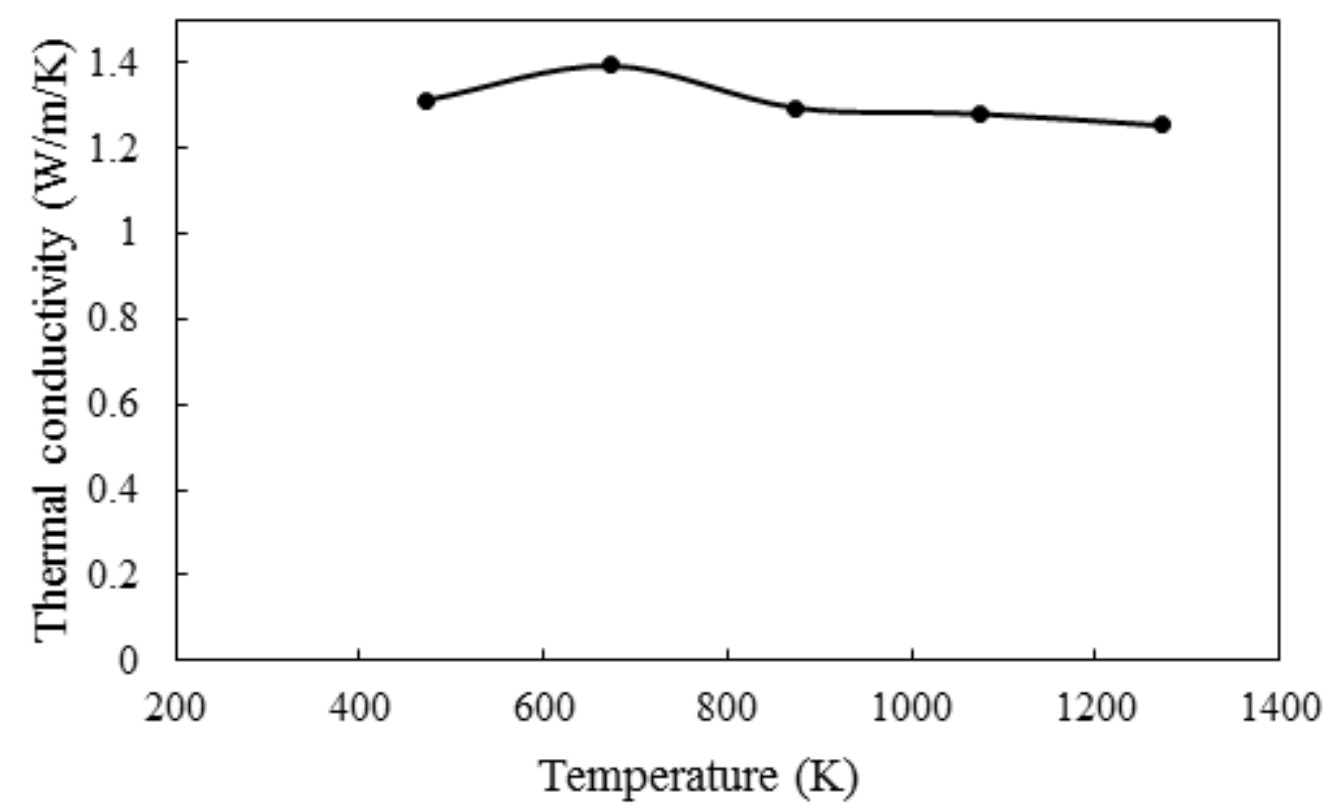

Figure 4: Temperature -dependent thermal conductivity of $\mathrm{La}_{2} \mathrm{Zr}_{2} \mathrm{O}_{7}$ single crystal using the RNEMD method

\section{2 $\mathrm{La}_{2} \mathrm{Zr}_{2} \mathrm{O}_{7}$ polycrystalline coating thermal conductivity calculations} using image based FE method

For porous $\mathrm{La}_{2} \mathrm{Zr}_{2} \mathrm{O}_{7}$ polycrystalline coating samples, a representative SEM image of $\mathrm{La}_{2} \mathrm{Zr}_{2} \mathrm{O}_{7}$ free standing coating is used as shown in Fig. 5a. The simulated temperature contour in the sample is shown in Fig. 5b. Comparing with the flash method experiment results in Fig.6, the FE method calculated thermal conductivity values are in the good agreement with the experiments results. The cracks and pores in the coating clearly reduce the thermal conductivity of the coatings about half from the single crystal conductivity in Fig. 4. 


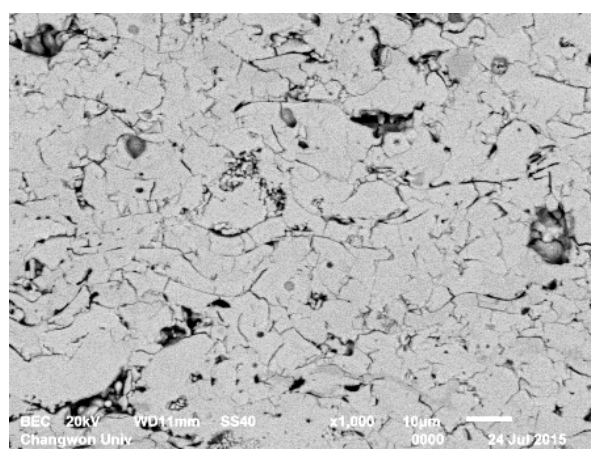

(a)

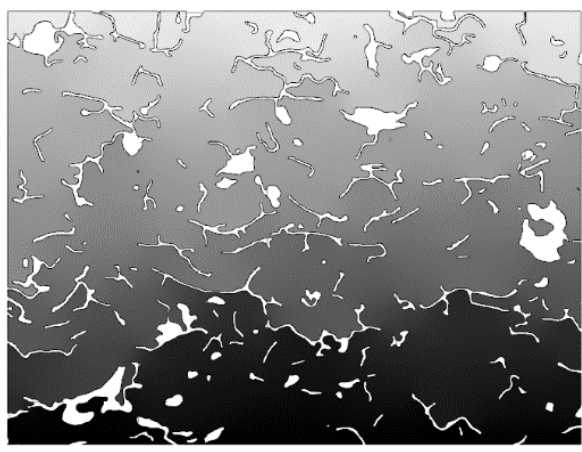

(b)

Fig. 5 (a) SEM image and (b) calculated temperature contours of $\mathrm{La}_{2} \mathrm{Zr}_{2} \mathrm{O}_{7}$

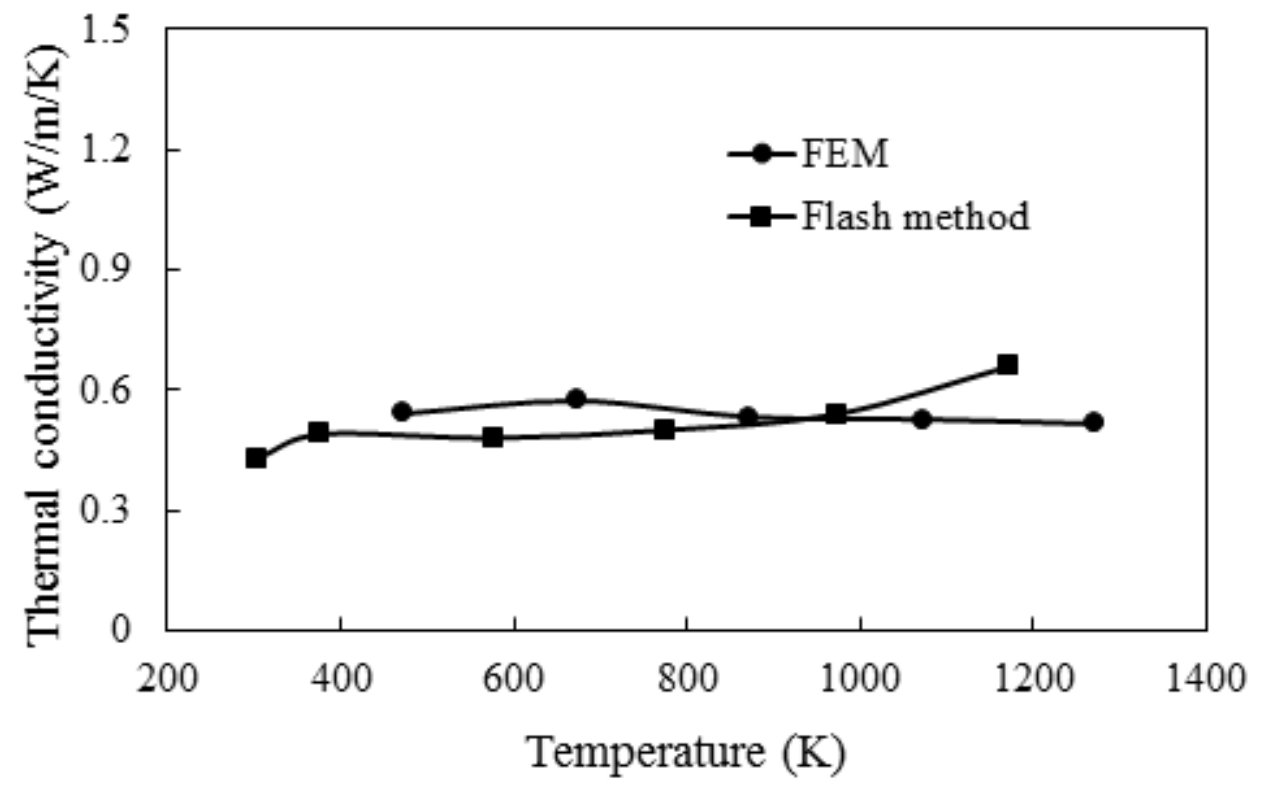

Figure 6: Thermal conductivity of $\mathrm{La}_{2} \mathrm{Zr}_{2} \mathrm{O}_{7}$ coating - $\mathrm{FE}$ method prediction and flash method

\section{3 $\mathrm{La}_{2} \mathrm{Zr}_{2} \mathrm{O}_{7}$ polycrystalline coatings thermal conductivity from experimental measurements}

Using the flash method, the averaged thermal conductivity measured from three samples is given in Fig. 6, which ranges from 0.44 to $0.62 \mathrm{~W} / \mathrm{m} / \mathrm{K}$ in the temperature range of 300 1200 K. The measured thermal conductivity is relatively constant below $900 \mathrm{~K}$, and slightly increases above $900 \mathrm{~K}$. 
In the pulsed thermal image-multilayer analysis method, the optical image of $\mathrm{La}_{2} \mathrm{Zr}_{2} \mathrm{O}_{7}$ coating specimen, thermal conductivity map, and heat capacity map are shown in Fig. 7. The measured product of heat capacity is $\sim 2.16 \times 10^{-6} \mathrm{~J} / \mathrm{m}^{3} / \mathrm{K}$. The average thermal conductivity measured by the PTI-MLA technique is $0.55 \mathrm{~W} / \mathrm{m} / \mathrm{K}$, which is also consistent with the flash method result and FE model in Fig.6.

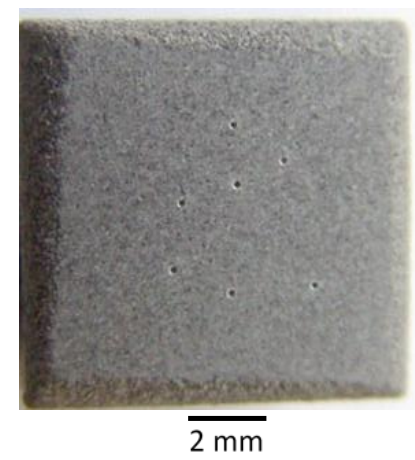

(a)

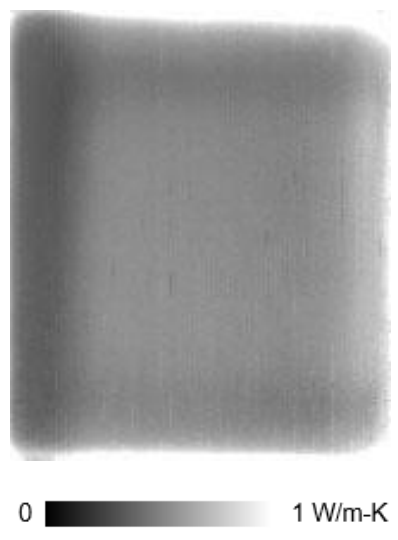

(b)

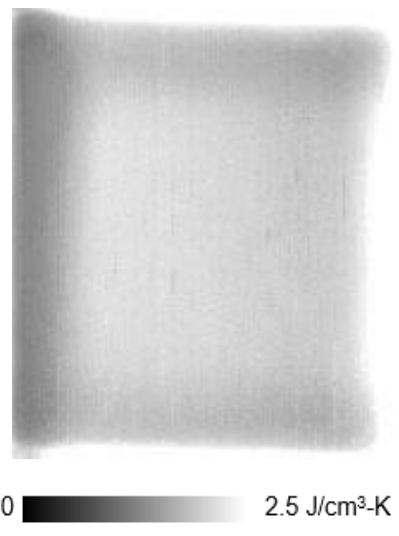

(c)

Figure 7: $\mathrm{La}_{2} \mathrm{Zr}_{2} \mathrm{O}_{7}$ coating (a) optical image; (b) thermal conductivity map; (c) product of heat capacity ( $\rho c)$ map

\section{Conclusions}

In this work, a novel image based multi-scale simulation framework combining molecular dynamics and finite element calculations has been proposed to study the thermal conductivity of $\mathrm{La}_{2} \mathrm{Zr}_{2} \mathrm{O}_{7}$ coatings. Experimental validations include the flash method and pulsed thermal image-multilayer analysis technique to measure the coating thermal conductivity. The main conclusions are summarized below:

1. The calculated thermal conductivity of $\mathrm{La}_{2} \mathrm{Zr}_{2} \mathrm{O}_{7}$ single crystal ranges from 1.25 $1.39 \mathrm{~W} / \mathrm{m} / \mathrm{K}$ in the temperature range of $473 \sim 1273 \mathrm{~K}$, using RNEMD method. 
2. Using the image-based FE method and single crystal thermal conductivity data, the calculated thermal conductivities of porous $\mathrm{La}_{2} \mathrm{Zr}_{2} \mathrm{O}_{7}$ polycrystalline are in the range of $0.46 \sim 0.59 \mathrm{~W} / \mathrm{m} / \mathrm{K}$ at the temperature range of $473 \sim 1273 \mathrm{~K}$. The predicted FE data are in good agreement with the flash method, 0.44 to $0.62 \mathrm{~W} / \mathrm{m} / \mathrm{K}$, in the temperature range of $300 \sim 1200 \mathrm{~K}$, and the PTI-MLA technique, $0.55 \mathrm{~W} / \mathrm{m} / \mathrm{K}$.

3. The image-based multi-scale simulation framework proposed in this work provides a powerful tool for future design of advanced coating systems.

\section{Acknowledgement}

J.Z. acknowledges the financial support provided by the US. Department of Energy (Award Number: DE-FE0008868; Project Title: Novel Functionally Graded Thermal Barrier Coatings in Coal-fired Power Plant Turbines; Program Manager: Richard Dunst) and Indiana University Research Support Funds Grant (RSFG) and International Research Development Fund (IRDF). Y.J. acknowledges the financial support provided by a National Research Foundation of Korea (NRF) grant funded by the Korean Government (MEST) (2011-0030058), and by Changwon National University in 2015 2016. J.S. acknowledges the support provided by the U.S. Department of Energy, Office of Fossil Energy, Crosscutting Research Program. 


\section{References}

[1] N. P. Padture, M. Gell, and E. H. Jordan, "Thermal Barrier Coatings for GasTurbine Engine Applications," Science, vol. 296, pp. 280-284, 2002.

[2] S. B. Weber, H. L. Lein, T. Grande, and M.-A. Einarsrud, "Lanthanum zirconate thermal barrier coatings deposited by spray pyrolysis," Surface and Coatings Technology, vol. 227, pp. 10-14, 2013.

[3] D. R. Clarke, M. Oechsner, and N. P. Padture, "Thermal-barrier coatings for more efficient gas-turbine engines," MRS Bulletin, vol. 37, pp. 891-898, 2012.

[4] D. Clarke and C. Levi, "Materials design for the next generation thermal barrier coatings," Annual Review of Materials Research, vol. 33, pp. 383-417, 2003.

[5] R. Vassen, X. Cao, F. Tietz, D. Basu, and D. Stöver, "Zirconates as New Materials for Thermal Barrier Coatings," Journal of the American Ceramic Society, vol. 83, pp. 2023-2028, 2000.

[6] X. Q. Cao, R. Vassen, W. Jungen, S. Schwartz, F. Tietz, and D. Stöver, "Thermal Stability of Lanthanum Zirconate Plasma-Sprayed Coating," Journal of the American Ceramic Society, vol. 84, pp. 2086-2090, 2001.

[7] W. J. Parker, R. J. Jenkins, C. P. Butler, and G. L. Abbott, "Flash Method of Determining Thermal Diffusivity, Heat Capacity, and Thermal Conductivity," Journal of Applied Physics, vol. 32, pp. 1679-1684, 1961.

[8] ASTM E1461-11, 2011 Standard Test Method for Thermal Diffusivity by the Flash Method, ASTM International, West Conshohocken, PA.

[9] D. Zhu, N. P. Bansal, and R. A. Miller, "Thermal Conductivity and Stability of HfO2-Y2O3 and La2Zr2O7 Evaluated for $1650 \mathrm{C}$ Thermal/Environmental Barrier Coating Applications," in Proceedings of the 105th Annual Meeting and Exposition of the American Ceramic Society, The American Ceramic Society, Nashville, TN, 2003.

[10] N. P. Bansal and D. Zhu, "Effects of doping on thermal conductivity of pyrochlore oxides for advanced thermal barrier coatings," Materials Science and Engineering: A, vol. 459, pp. 192-195, 2007.

[11] X. Guo, Z. Lu, Y.-G. Jung, L. Li, J. Knapp, and J. Zhang, "Thermal properties, thermal shock and thermal cycling behavior of lanthanum zirconate based thermal barrier coatings," Metallurgical and Materials Transactions E (DOI: 10.1007/s40553-016-0070-4), 2016.

[12] P. K. Schelling , S. R. Phillpot , and R. W. Grimes, "Optimum pyrochlore compositions for low thermal conductivity," Philosophical Magazine Letters, vol. 84, pp. 127-137, 2004/02/01 2004.

[13] A. Maiti, G. D. Mahan, and S. T. Pantelides, "Dynamical simulations of nonequilibrium processes - Heat flow and the Kapitza resistance across grain boundaries," Solid State Communications, vol. 102, pp. 517-521, 1997.

[14] R. Kubo, Statistical Physics II Nonequilibrium Statistical Mechanics, Second edition.. ed. Berlin, Heidelberg: Berlin, Heidelberg : Springer Berlin Heidelberg, 1991.

[15] J. Che, T. Çağın, W. Deng, and W. A. Goddard III, "Thermal conductivity of diamond and related materials from molecular dynamics simulations," The Journal of Chemical Physics, vol. 113, pp. 6888-6900, 2000. 
[16] P. K. Schelling, S. R. Phillpot, and P. Keblinski, "Comparison of atomic-level simulation methods for computing thermal conductivity," Physical Review B, vol. 65, p. 144306, 2002.

[17] F. Müller-Plathe, "A simple nonequilibrium molecular dynamics method for calculating the thermal conductivity," The Journal of Chemical Physics, vol. 106, pp. 6082-6085, 1997.

[18] F. Müller-Plathe, "Reversing the perturbation in nonequilibrium molecular dynamics: An easy way to calculate the shear viscosity of fluids," Physical Review E, vol. 59, pp. 4894-4898, 1999.

[19] X. Guo and J. Zhang, "First Principles Study of Thermodynamic Properties of Lanthanum Zirconate," Materials Today: Proceedings, vol. 1, pp. 25-34, 2014.

[20] X. Guo, J. Zhang, Y.-G. Jung, L. Li, and J. Knapp, "Ab Initio Study of Thermal Properties of Lanthanum Zirconate," presented at the Materials Science \& Technology 2014 (MS\&T), Pittsburgh, Pennsylvania, USA, 2014.

[21] L. Wang, D. C. Li, J. S. Yang, F. Shao, X. H. Zhong, H. Y. Zhao, et al., "Modeling of thermal properties and failure of thermal barrier coatings with the use of finite element methods: A review," Journal of the European Ceramic Society, vol. 36, pp. 1313-1331, 2016.

[22] X. G. Jing Zhang, Yeon -Gil Jung, Li Li, James Knapp, "Quantitative analysis of pore morphology in lanthanum zirconate thermal barrier coating," Materials Science and Technology (MS\&T) 2014, pp. 2061-2068, October 12-16 2014.

[23] J. Zhang, X. Guo, Y.-G. Jung, L. Li, and J. Knapp, "Microstructural Nonuniformity and Mechanical Property of Air Plasma-sprayed Dense Lanthanum Zirconate Thermal Barrier Coating," Materials Today: Proceedings, vol. 1, pp. 11-16, 2014.

[24] L. Wang, Y. Wang, X. G. Sun, Z. Y. Pan, J. Q. He, and C. G. Li, "Influence of pores on the surface microcompression mechanical response of thermal barrier coatings fabricated by atmospheric plasma spray-Finite element simulation," Applied Surface Science, vol. 257, pp. 2238-2249, 2011.

[25] M. Arai, H. Ochiai, and T. Suidzu, "A novel low-thermal-conductivity plasmasprayed thermal barrier coating controlled by large pores," Surface and Coatings Technology, vol. 285, pp. 120-127, 2016.

[26] J. H. Keyak, J. M. Meagher, H. B. Skinner, and C. D. Mote, "Automated threedimensional finite element modelling of bone: a new method," Journal of Biomedical Engineering, vol. 12, pp. 389-397, 1990.

[27] Z. Wang, A. Kulkarni, S. Deshpande, T. Nakamura, and H. Herman, "Effects of pores and interfaces on effective properties of plasma sprayed zirconia coatings," Acta Materialia, vol. 51, pp. 5319-5334, 2003.

[28] Y. Wang, J. Hua, Z. Liu, Y. Zeng, Y. Zhou, and H. Wang, "Melting index characterization and thermal conductivity model of plasma sprayed YSZ coatings," Journal of the European Ceramic Society, vol. 32, pp. 3701-3707, 2012.

[29] ImageJ. Available: https://imagej.nih.gov/ij/

[30] COMSOL. (2016). Available: https://www.comsol.com/

[31] B. Nair, J. Singh, and M. Grimsditch, "A model for residual stress evolution in air-plasma-sprayed zirconia thermal barrier coatings," in 24th Annual Conference 
on Composites, Advanced Ceramics, Materials, and Structures-A: Ceramic Engineering and Science Proceedings, 2009, p. 133.

[32] H. Lehmann, D. Pitzer, G. Pracht, R. Vassen, and D. Stöver, "Thermal Conductivity and Thermal Expansion Coefficients of the Lanthanum Rare-EarthElement Zirconate System," Journal of the American Ceramic Society, vol. 86, pp. 1338-1344, 2003.

[33] J. Sun, "Pulsed Thermal Imaging Measurement of Thermal Properties for Thermal Barrier Coatings Based on a Multilayer Heat Transfer Model," Journal of Heat Transfer, vol. 136, p. 081601, 2014. 